\title{
Pharmacokinetic Study of Isoniazid and Rifampicin in Patients Suffering from Antitubercular Drugs (ATD) Induced Hepatotoxicity
}

\section{Rath $\mathbf{R}^{1}$ and Tevatia $\mathbf{S}^{2 *}$}

${ }^{1}$ Department of Pharmacology, I.T.S. Centre for Dental Studies and Research, Muradnagar, Ghaziabad, Uttar Pradesh, India

${ }^{2}$ Department of Periodontology and Implantology, I.T.S. Centre for Dental Studies and Research, Muradnagar, Ghaziabad, Uttar Pradesh, India

\begin{abstract}
Various drugs have been used for the treatment of antitubercular treatment. Such drugs may often lead to hepatotoxicity.
\end{abstract}

Aim: To Access the pharmacokinetic profile of rifampicin and isoniazid and metabolites of isoniazid viz. Mono Acetyl Hydrazine (MAH) and Diacetyl Hydrazine (DAH) in patients of pulmonary tuberculosis which served as control group and in patients of Antitubercular Drugs (ATD) induce hepatotoxicity.

Materials and methods: Ten patients of pulmonary tuberculosis already receiving ATD for at least last four weeks and had no clinical hepatotoxicity and ten patients of pulmonary tuberculosis suffering from ATD induced hepatotoxicity were included. Liver Function Test Serum bilirubin, SGOT, SGPT, Serum Alkaline phosphatase, Prothrombin time, $\mathrm{HbsAg}$, IgM anti $\mathrm{HBc}$ for hepatitis B, blood urea and serum creatinine were investigated.

Results: Patients suffering from ATD induced hepatotoxicity have shown increased peak serum Conc. $t_{1 / 2}$ and decrease in serum clearance of INH and increase in peak serum concentration, AUC \& decrease clearance of RMP indicating that there was delayed elimination of both the drugs (RMP, INH) which may further cause hepatotoxicity.

Conclusion: It was concluded that in patients of liver derangement low dose of $\mathrm{INH}$ and rifampicin should be given and plasma levels of MAH may act as an indicator to predict hepatotoxicity in patients receiving antitubercular treatment.

Keywords: Antitubercular therapy; Rifampicin; Isoniazid; Hepatotoxicity

Abbreviation: IH: Isoniazid; MAH: Mono Acetyl Hydrazine; DAH: Diacetyl Hydrazine; INH: Isonicotinylhydrazide

\section{Introduction}

The development of highly effective short course chemotherapy for the treatment of pulmonary tuberculosis was made possible by the introduction of combined isoniazid and rifampicin containing regimens. Serious side effects attributed to isoniazid or rifampicin treatment is rare [1]. However, one of the most important toxic manifestations is clinical hepatitis with Jaundice which occurs with an incidence of about 1-3\% and the incidence of hepatotoxicity increases to $8-10 \%$ when isoniazid is given along with rifampicin [2].

The pathogenesis of isoniazid induced injury in human is unclear. The clinical features of a few patients suggest a hypersensitivity reaction to the drug [3]. However, the involvement of the immunoallergic system has not been shown consistently [4]. The majority of patients do not show any sign of symptoms commonly associated with a hypersensitivity reaction. Studies in animals have shown that one of the metabolite of isoniazid acetyl hydrazine is a potent hepatotoxic [5]. Acetyl hydrazine requires metabolic activation by the hepatotoxygenase system to a reactive intermediate that covalently binds to apparently vital hepatic macromolecules to exert its toxic effects.

Enhanced incidence of hepatotoxicity when INH and rifampicin are co-administered has been proposed to be due to enzyme inducing activity of rifampicin which may result into formation of excessive reactive metabolite from Mono Acetyl Hydrazine (MAH) [2]. Moreover, both INH and rifampicin are metabolised by the liver. In the presence of hepatic derangement induced by $\mathrm{INH}$, kinetic profile of both the drugs may get affected.
The kinetics data of INH and its metabolites MAH and DAH has been investigated only in the urine of healthy volunteers [6]. There is no report where $\mathrm{MAH}$ and DAH has been estimated in plasma either in volunteers or in patients. Moreover, pharmacokinetic profile of INH, its metabolites and rifampicin in patients of AID induced hepatotoxicity has not been reported.

The present study was undertaken to assess the pharmacokinetic profile of rifampicin, INH and metabolites INH viz. MAH and DAH in patients of pulmonary tuberculosis which served as control group and in patients of Antitubercular Drugs (ATD) induce hepatotoxicity.

\section{Materials and Methods}

\section{Study design}

Controlled Longitudinal study was conducted.

\section{Inclusion criteria}

Adult patients of either sex, between age group of 25-50 years, receiving antitubercular therapy (INH+Rifampicin+ Pyrazinamide and

*Corresponding author: TevatiaS, DepartmentofPeriodontology and Implantology I.T.S. Centre for Dental Studies and Research, Muradnagar, Ghaziabad, Uttar Pradesh, India, Tel: +91-9654086903; E-mail: dr.siddharthtevatia@gmail.com

Received August 22, 2016; Accepted November 11, 2016; Published November 22, 2016

Citation: Rath R, Tevatia S (2016) Pharmacokinetic Study of Isoniazid and Rifampicin in Patients Suffering from Antitubercular Drugs (ATD) Induced Hepatotoxicity. J Bioequiv Availab 8: 290-293. doi: 10.4172/jbb.1000312

Copyright: (c) 2016 Rath $\mathrm{R}$, et al. This is an open-access article distributed under the terms of the Creative Commons Attribution License, which permits unrestricted use, distribution, and reproduction in any medium, provided the original author and source are credited. 
Citation: Rath R, Tevatia S (2016) Pharmacokinetic Study of Isoniazid and Rifampicin in Patients Suffering from Antitubercular Drugs (ATD) Induced Hepatotoxicity. J Bioequiv Availab 8: 290-293. doi: 10.4172/jbb.1000312

isoniazid or ethambutol) for pulmonary tuberculosis atleast for four weeks and had not developed hepatoxicity were included in the study. Adult pulmonary tuberculosis patients of either sex suffering from ATD induced hepatotoxicity were included in the study.

\section{Exclusion criteria}

Sputum positive patient of pulmonary tuberculosis, pregnant women, lactating mothers and any patient suffering from viral hepatitis, diabetes mellitus, cardiac and renal diseases were excluded from the study.

\section{Investigations}

Following laboratory investigations were carried out in all patients:

1. Liver Function Test Serum bilirubin, SGOT, SGPT, Serum Alkaline phosphatase, Prothrombin time.

2. To exclude presence of viral hepatitis, the following investigations were done:

a) $\mathrm{HbsAg}$, IgM anti $\mathrm{HBc}$ for hepatitis $\mathrm{B}$.

b) Anti HCV (IIIrd Generation EIA) for hepatitis C.

c) IgM anti HAV for hepatitis A.

3. To exclude renal impairment, the following investigations were done:

a) Blood urea.

b) Serum creatinine.

4. Blood glucose level-fasting and post prandial was done to exclude mellitus.

5. Sputum examination for acid fast bacilli was done to exclude sputum positive cases.

\section{Subject allocation}

Group-I: Ten patients of pulmonary tuberculosis already receiving ATD for at least last four weeks and had no clinical hepatotoxicity.

Group-II: Ten patients of pulmonary tuberculosis suffering from ATD induced hepatotoxicity.

\section{Methods}

\section{Group I}

To study the pharmacokinetic pattern of rifampicin, INH and INH metabolites in patients who have not developed hepatotoxicity, the study was conducted in ten patients of sputum negative pulmonary tuberculosis with normal liver and kidney function tests who were already receiving ATD atleast for the last four weeks. Patients were admitted in the hospital for two days. On the study day after an overnight fast, $450 \mathrm{mg}$ of rifampicin and $300 \mathrm{mg}$ of INH were administered orally with a glass of water. Blood samples were collected at $0,1 / 2,12,4,6,8$ 12 and $24 \mathrm{~h}$ and their levels were estimated.

\section{Group II}

Ten patients who were admitted in the hospital with a diagnosis of ATD induced hepatotoxicity and patients who got clinically detectable jaundice were enrolled in the study. Drug induced hepatotoxicity was established by casual assessment as described by WHO and was confirmed by dechallenge test i.e., drugs (INH, rifampicin and pyrazinamide) were stopped immediately. Blood samples were collected at the same time intervals as mentioned above after the administration of rifampicin and INH and plasma levels of INH, rifampicin and INH metabolites were estimated.

Estimation of plasma levels of INH and its metabolites was done by spectrophotometer method described by Ellard et al. [7] and estimation of rifampicin plasma level was done by spectrophotometer method described by Gupta [8]. From plasma concentration time curve, pharmacokinetic parameters viz. $\mathrm{C}_{\max }$ (maximum concentration), $\mathrm{T}_{\max }$ (Time taken to reach the maximum concentration), $\mathrm{t}_{1 / 2}$ (half-life), AUC (Area under plasma concentration time curve and plasma clearance were calculated and compared. Data was analysed by student's paired ' $t$ ' test.

\section{Results}

In group II, the ATD viz INH, rifampicin, pyrazinamide was stopped and alternative Antitubercular Drugs (ATD) were administered (streptomycin and ciprofloxacin). Patients' clinical condition started improving after stopping the drugs and liver function test returned to normal level.

Figure 1 and Table 1 shows the plasma concentration time curve and values of pharmacokinetic parameters of INH in both groups of patients. It was observed that $\mathrm{C}_{\max },(\mathrm{ug} / \mathrm{ml}) \mathrm{T}_{\max }(\mathrm{h}), \mathrm{t}_{1 / 2}(\mathrm{~h})$ and $\mathrm{AUC}(0$ 24) $(\mathrm{ug} / \mathrm{h} / \mathrm{m} 1)$ were increased significantly in group II as compared to group I. There was no difference in KCL (h) in both the groups. Plasma clearance decreased significantly in group II, Figure 2 and Table 2 shows plasma concentration time curve and values of pharmacokinetic parameters of $\mathrm{MAH}$ in both groups. It was observed the $\mathrm{C}_{\max }, \mathrm{t}_{1 / 2}$ and $\mathrm{AUC}_{(0-24)}$ decreased significantly in group II. However, $\mathrm{T}_{\max }$ and KCL did not change significantly.

Figure 3 and Table 3 shows the plasma concentration time curve and values of pharmacokinetic parameters of rifampicin in both groups. It was observed that $\mathrm{C}_{\max }$ and $\mathrm{AUC}_{(0-24)}$ increased significantly in group II whereas plasma clearance decreased significantly. However, $\mathrm{T}_{\max }, \mathrm{t}_{1 / 2}$

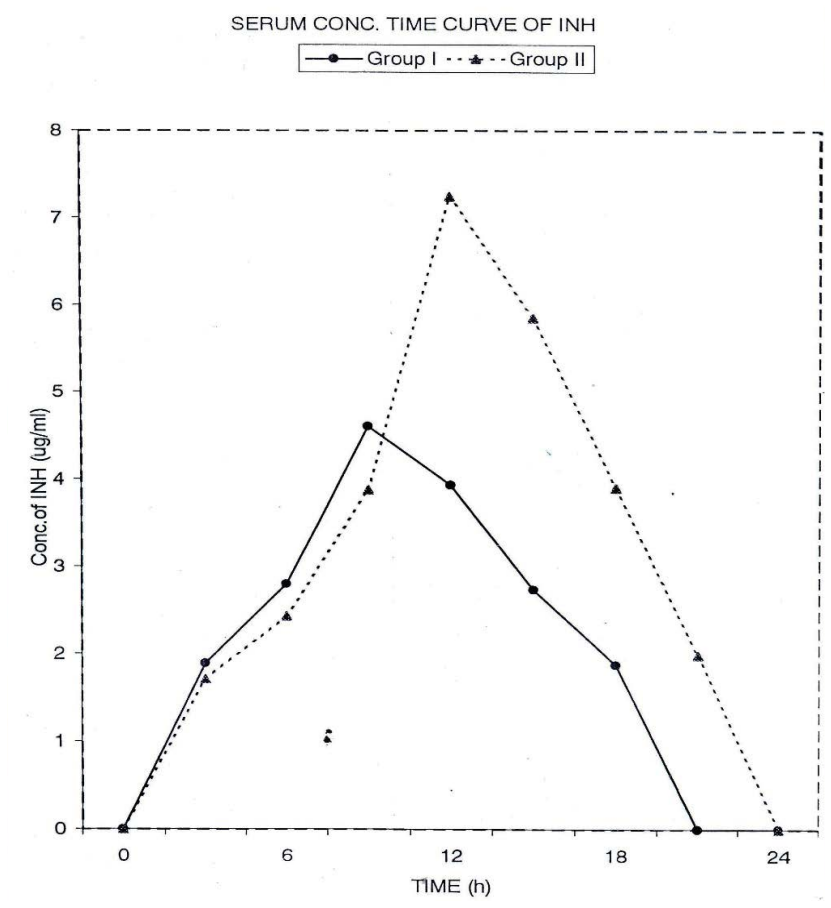

Figure 1: Flow chart indicating the methodology implemented in the present clinical study. 
Citation: Rath R, Tevatia S (2016) Pharmacokinetic Study of Isoniazid and Rifampicin in Patients Suffering from Antitubercular Drugs (ATD) Induced Hepatotoxicity. J Bioequiv Availab 8: 290-293. doi: 10.4172/jbb.1000312

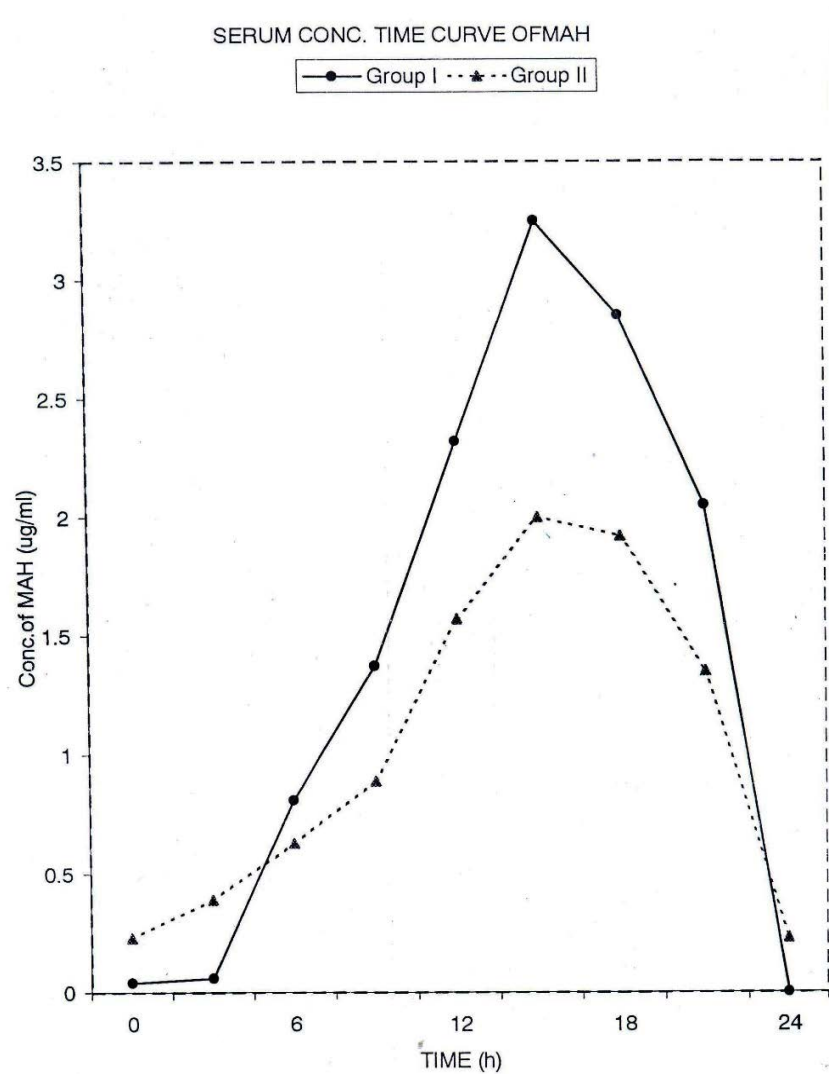

Figure 2: The plasma concentration time curve and values of pharmacokinetic parameters of MAH in both groups of patients.

\begin{tabular}{|c|c|c|}
\hline $\begin{array}{c}\text { Pharmacokinetic } \\
\text { Parameters }\end{array}$ & $\begin{array}{c}\text { Group-1 } \\
(\mathbf{n}=\mathbf{1 0})\end{array}$ & $\begin{array}{c}\text { Group-2 } \\
(\mathbf{n}=\mathbf{1 0})\end{array}$ \\
\hline $\mathrm{C}_{\max }(\mu \mathrm{g} / \mathrm{ml})$ & $4.09 \pm 0.29$ & $6.740 \pm 0.40^{\star}$ \\
\hline $\mathrm{T}_{\max }(\mathrm{h})$ & $2.20 \pm 0.19$ & $3.60 \pm 0.31^{* *}$ \\
\hline $\mathrm{t}_{1 / 2}$ & $3.29 \pm 0.15$ & $4.20 \pm 0.27^{\star}$ \\
\hline $\mathrm{Kel}(\mathrm{h})$ & $0.21 \pm 0.0009$ & $0.17 \pm 0.014$ \\
\hline $\mathrm{AUC}_{(0-24)} \mu \mathrm{g} / \mathrm{h} / \mathrm{ml}$ & $29.33 \pm 1.44$ & $60.77 \pm 5.11^{* *}$ \\
\hline $\mathrm{Cl}(\mathrm{L} / \mathrm{h})$ & $10.47 \pm 0.57$ & $5.42 \pm 0.66^{* *}$ \\
\hline & $\mathrm{P}<0.05^{*}$ & $\mathrm{P}<0.001^{* *}$ \\
\hline
\end{tabular}

Table 1: Comparative pharmacokinetic profile of isoniazid in two groups.

\begin{tabular}{|c|c|c|}
\hline $\begin{array}{c}\text { Pharmacokinetic } \\
\text { Parameters }\end{array}$ & $\begin{array}{c}\text { Group-1 } \\
(\mathbf{n = 1 0 )}\end{array}$ & $\begin{array}{c}\text { Group-2 } \\
(\mathbf{n = 1 0 )}\end{array}$ \\
\hline $\mathrm{C}_{\max }(\mu \mathrm{g} / \mathrm{ml})$ & $3.25 \pm 0.087$ & $2.00 \pm 0.06^{* *}$ \\
\hline $\mathrm{T}_{\max }(\mathrm{h})$ & $6.00 \pm 0.02$ & $6.00 \pm 0.00$ \\
\hline $\mathrm{t}_{1 / 2}$ & $9.19 \pm 0.02$ & $8.28 \pm 0.07^{*}$ \\
\hline $\mathrm{Kel}(\mathrm{h})$ & $0.75 \pm 1.87$ & $0.083 \pm 0.073$ \\
\hline $\mathrm{AUC}_{(0-24)} \mu \mathrm{g} / \mathrm{h} / \mathrm{ml}$ & $39.02 \pm 1.96$ & $27.20 \pm 1.24^{* *}$ \\
\hline & $\mathrm{P}<0.05^{*}$ & $\mathrm{P}<0.001^{* *}$ \\
\hline
\end{tabular}

Table 2: Comparative pharmacokinetic profile of mono acetyl hydrazine in two groups.

and KCL did not show any significant change.

Pharmacokinetic profile of DAH did not differ in two groups.

\section{Discussion}

Isoniazid and rifampicin both are metabolized in the liver and both are known to cause hepatotoxicity. Under such conditions, it is of paramount importance to know the pharmacokinetic profile of both these agents in hepatic derangement.

Acocella et al. [9] studied the pharmacokinetics of single dose of INH $(600 \mathrm{mg})$ in the subjects suffering from chronic liver disease. They showed a significant increase in serum concentration and increase in plasma half-life of isoniazid.

In the present study, it has been shown that in patients who were receiving ATD and had developed hepatotoxicity, there was significant increase in $\mathrm{C}_{\max }, \mathrm{t}_{1 / 2}$ and $\mathrm{ALT}_{(0-24)} \mathrm{h}$ of INH as compared to the control group. On the other hand, plasma clearance decreased significantly indicating that INH metabolism decreased thus giving rise to higher level of INH, which may further add to hepatotoxicity. Likewise, $\mathrm{C}_{\max }$ and AUC of rifampicin increased in group II as compared to group I while plasma clearance decreased significantly indicating decreased metabolism of rifampicin in these patients.

In the present study, we have also estimated the levels of metabolite of INH (MAH and diacetyl hydrazine). The hepatic damage caused by INH is believed to be due to metabolite of INH [3]; MAH has been

\begin{tabular}{|c|c|c|}
\hline $\begin{array}{c}\text { Pharmacokinetic } \\
\text { Parameters }\end{array}$ & $\begin{array}{c}\text { Group-1 } \\
\text { (n=10) }\end{array}$ & $\begin{array}{c}\text { Group-2 } \\
(\mathbf{n = 1 0 )}\end{array}$ \\
\hline $\mathrm{C}_{\max }(\mu \mathrm{g} / \mathrm{ml})$ & $4.48 \pm 0.32$ & $6.00 \pm 0.55^{*}$ \\
\hline $\mathrm{T}_{\max }(\mathrm{h})$ & $2.10 \pm 0.23$ & $2.00 \pm 0.19$ \\
\hline $\mathrm{t}_{1 / 2}$ & $3.50 \pm 0.20$ & $4.23 \pm 0.14$ \\
\hline $\mathrm{Kel}(\mathrm{h})$ & $0.10 \pm 0.01$ & $0.16 \pm 0.005$ \\
\hline $\mathrm{AUC}_{(0-24)} \mu \mathrm{g} / \mathrm{h} / \mathrm{ml}$ & $29.30 \pm 2.61$ & $48.19 \pm 3.32^{*}$ \\
\hline $\mathrm{Cl}(\mathrm{lit} / \mathrm{h})$ & $17.03 \pm 1.59$ & $9.75 \pm 0.65^{* *}$ \\
\hline & $\mathrm{P}<0.05^{*}$ & $\mathrm{P}<0.001^{* *}$ \\
\hline
\end{tabular}

Table 3: Comparative pharmacokinetic profile of rifampicin in two groups.

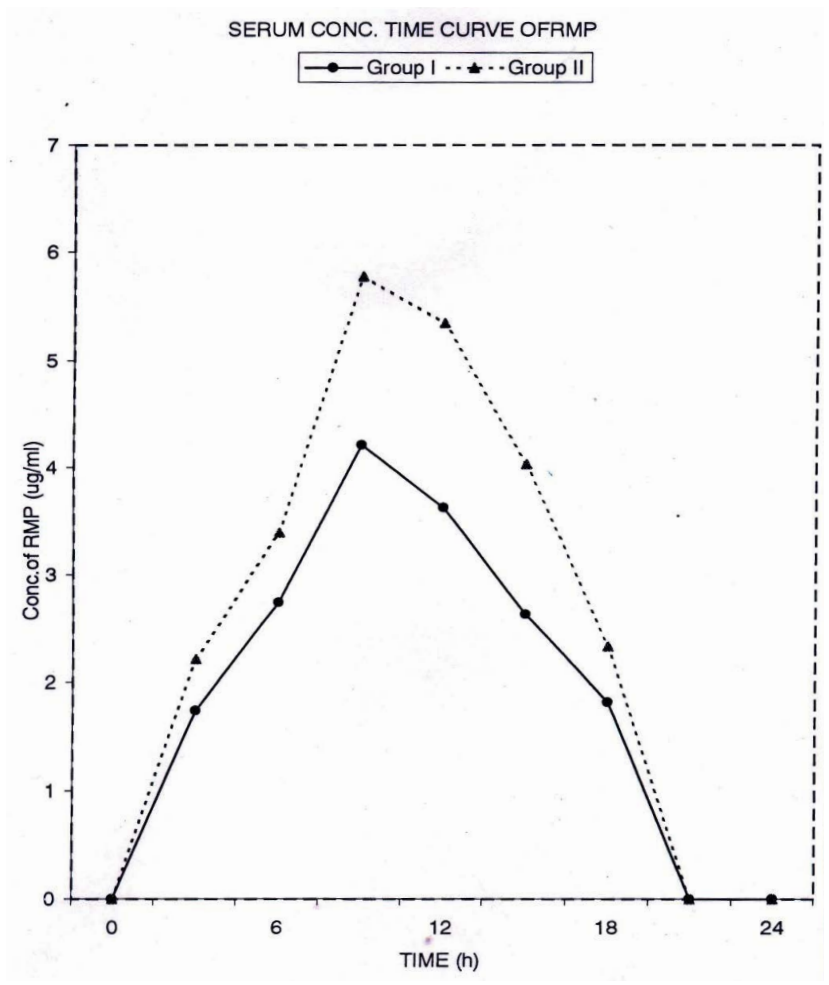

Figure 3: The plasma concentration time curve and values of pharmacokinetic parameters of rifampicin in both groups of patients. 
Citation: Rath R, Tevatia S (2016) Pharmacokinetic Study of Isoniazid and Rifampicin in Patients Suffering from Antitubercular Drugs (ATD) Induced Hepatotoxicity. J Bioequiv Availab 8: 290-293. doi: 10.4172/jbb.1000312

implicated for this action as it has been shown to be potent hepatotoxin in experimental animals [10].

Hepatotoxicity is dependent on further metabolism of MAH by microsomal enzyme to reactive metabolite [10]. It has been shown in animals that enhanced metabolism of MAH by phenobarbitone (an enzyme inducer) results into hepatic derangement [11]. Since rifampicin is also an enzyme inducer, it is possible that combined use of INH and rifampicin would result into greater hepatic insult. In the present study, it has been shown that $\mathrm{C}_{\text {max }}, \mathrm{t}_{1 / 2}$ and AIX of MAH decreased significantly in group II as compared to group I indicating, even though the level of INH were higher but levels of MAH decreased. Perhaps more of MAH was converted into reactive metabolite leading to hepatotoxicity.

\section{Conclusion}

- Patients suffering from ATD induced hepatotoxicity have shown increased peak serum conc. $t_{1 / 2}$ and decrease in serum clearance of INH and increase in peak serum concentration, AUC \& decrease clearance of RMP indicating that there was delayed elimination of both the drugs (RMP, INH) which may further cause hepatotoxicity.

- Hence it is concluded from this study that in patients with liver derangement, one would require to give low dose of INH and rifampicin.

- Plasma levels of MAH may act as an indicator to predict hepatotoxicity in patients receiving antitubercular treatment.

\section{References}

1. Giriling DJ, Fox W (1982) The role of Pyrazinamide in the modern treatment of tuberculosis. WHO/TB 82: 134-140.

2. Sarma GR, Immanuel C, Kailasam S, Narayana ASL, Venkatesan P (1985) Rifampicin-Induced release of hydrazine from Isoniazid. Indian J Med Res 30: 1072-1077.

3. Mitchell JR, Zimmerman HJ, Ishok KG, Throgeirson UP, Timbrell JR, et al. (1976) INH liver, injury, clinical spectrum, pathology, probable pathogenesis. Ann Int Med 84: 181-192.

4. Dove JT, Chaparas SD, Hedrick SR (1972) Failure to demonstrate trans formation lymphocytes of patients with Isoniagnizd associated hepatitits. Am Rev Resp Dis 106: 485-487.

5. Nelson SD, Mitchell JR, Timbrell JA, Snoodgrass WR, Corcoran GB (1976) Isoniazid and iproniazid: activation of metabolites to toxic intermediates in man and rat. Science 193: 901-903.

6. Timbrell JA, Wright JM (1984) Urinary metabolite profile of Isoniazid in patient who develop Isoniazid relation liver damage. Hum Exp Toxicol 3: 485-495.

7. Ellard GA, Gammon PT, Wallace SM (1972) The determination of isoniazid and its metabolites acetyl isoniazd, monoacetylehydraine, diacetylhydrazine isonicotinic acid and isonicotinylglyane in serum and urine. Biochem J 26: 449458.

8. Gupta PR, Purohit SD, Mehta YR, Jain BL, Koolwal S, et al. (1995) Serum and urinary rifampicin and heptic toxicity. Ind J Tub 32: 86-90.

9. Acocella G, Bonallo L, Garimoldin M, Mainardi M, Tenconi LT, et al. (1972) Kinetics of Rifampicin and INH administered alone and in combination t-o normal subjects and patients with liver disease. Gut 13: 47-53.

10. Timbrell JA, James M, Wright MD, Thoman A (1977) Monoacetylhydrazine as metabolite of Isoniazid in man. Clin Pharmacol Ther 22: 602-608.

11. Timbrell JA, Mitchell JR, Snodrass WR, Nelson SD (1980) Isoniazid hepatotoxicity: The relationship between covalent binding and metabolism in vivo. J Pharmacol Exp Ther 213: 364-469. 